\title{
SWOT Analysis of China's Financial Cooperation With Russia Under the New Situation
}

\author{
Yanling Zhou ${ }^{1, *}$ Liqiang Zhai ${ }^{1}$
}

${ }^{1}$ The School of Economics and Management, Heihe University, Heihe, Heilongjiang 164300, China

*Corresponding author. Email: yanling365@163.com

\begin{abstract}
Financial cooperation between China and Russia is the main way to accelerate the economic development of the two countries. The emergence of the new situation has put forward new requirements for the development of bilateral cooperation, and exploring the best path for bilateral cooperation has become the key research content. This paper selects SWOT analysis method as the research tool and conducts a comprehensive analysis based on the advantages and disadvantages of the cooperation between the two countries, the threats they face during the development and the opportunities they may encounter as the research indicators. By constructing the development strategy model and formulating the cooperative development suggestions, this paper hopes to achieve the purpose of promoting China-Russian financial cooperation.
\end{abstract}

\section{Keywords: SWOT analysis, China-Russia financial cooperation, the new situation}

\section{INTRODUCTION}

The proposal of "the Belt and Road Initiative" has changed China's economic construction and development strategy, established the cooperative relationship between China and other countries, and opened up a new path for China's economic development [1]. Against this background, the strategy of promoting financial cooperation and development among countries along the Belt and Road is proposed. As Russia is an important financial cooperative partner of China, how to promote the financial and trade cooperation with it is the current priority for China [2]. In this paper, SWOT analysis method is adopted to comprehensively analyze the cooperation between the two countries under this situation, and a SWOT development strategy model is constructed to formulate a reliable financial cooperation development strategy.

\section{CURRENT SITUATION OF FINANCIAL COOPERATION BETWEEN CHINA AND RUSSIA UNDER THE NEW SITUATION}

\section{A. Continuous expansion in cooperation scope}

Since the beginning of the 21 st century, the two countries have witnessed rapid economic development

*Fund: This paper is the result of the Scientific Research Project of Basic Scientific Research Operating Expenses of Provincial Universities of Heilongjiang Education Department in 2019 "Provincial Colleges and Universities, Deepening Heilongjiang Province's Financial Cooperation Strategy with Russia Under the New Situation (2019-KYyWF-0472). and more and more frequent financial exchanges. At present, a cooperative financial system with central banks as the main body has been established between the two. The management system of the sub-committee was set up to handle listed transactions, local currency settlement, regulatory cooperation and other relevant cooperation issues, so as to ensure the smooth implementation of financial cooperation between the two countries [8]. By the end of 2019, the two countries set up branches respectively, strengthened their cooperation and reached agency cooperation agreements with a number of banks, which greatly expanded the scope of cooperation.

\section{B. Continuous expansion in cooperation field}

In the early stage of China-Russian cooperation, the degree of financial development was relatively low, which severely limited the areas of financial cooperation with only $2 \sim 4$ fields of financial cooperation involved . From 2016 to 2019, ChinaRussia cooperation focused on tourism, aerospace and other industries, enriched financial cooperation projects and expanded cooperation fields. Based on the current development trend and the contents of the 19th National Congress, the fields of bilateral cooperation will continue to expand.

\section{Innovation of cooperation models between the two countries}

With the rapid development of the Internet, the cooperation model between the two countries has been transformed from the traditional financial cooperation 
model to the Internet financial cooperation model. At present, the two countries have initially established an Internet financial cooperation model, and have completed some transactions of financial cooperation projects through the Internet platform [10]. Compared with the traditional offline cooperative operation mode, Internet finance can effectively and comprehensively grasp the basic information of cooperative projects, saving a lot of manpower and material resources. Although Internet finance is the breakthrough of ChinaRussia financial cooperation, offline cooperation has not been abandoned. Currently, bilateral financial cooperation is mainly based on the mode of dualchannel financial cooperation, and cooperation is established online and offline respectively, so as to promote the economic development of the two countries.

\section{ANALYSIS OF FINANCIAL COOPERATION BETWEEN CHINA AND RUSSIA BASED ON SWOT ANALYSIS METHOD}

In order to promote the financial cooperation between China and Russia, this paper chooses SWOT analysis method as the research tool and analyzes the advantages and disadvantages of the current financial cooperation between the two countries. It explores the opportunities and threats that may be encountered in the future cooperation, tries to cover up the disadvantages of cooperation with the advantages, firmly seize the opportunities encountered in the cooperation between China and Russia, and tries to avoid the threats during the cooperation as far as possible.

\section{A. Advantages of the financial cooperation}

1) The two economies complement each other: The economies of China and Russia are quite similar. Although China's economy is growing fast, its financial cooperation with Russia can have spillover effects, which not only bring considerable economic benefits to China, but also open up good economic development channels for Russia. From the current development situation, the cooperation between China and Russia can promote each other's economic development, and in the next 10 years, the financial cooperation between the two countries will enter the golden period of cooperation.

2) Reaching cooperation consensus and political mutual trust: China and Russia have gradually improved the financial cooperation system and reached consensus at the political level. At present, China has an open attitude towards the external economic development, while some developed countries have not implemented the economic opening-up policy. Therefore, the cooperative attitude has demonstrated
China's sincerity, which has been recognized by the Russian state.

3) Exchanging national cultures: Under normal circumstances, economic development is greatly influenced by culture, and the mutual exchange of culture can deepen the emotion and cognition between the two countries. In recent years, China and Russia have conducted frequent cultural exchanges and conducted in-depth research into each other's national cultures. According to statistics, by the end of 2019, Russia had opened Chinese ancient culture classes in more than 120 schools, telling about classical Chinese culture such as Confucius and Mozi. China also introduced Russian culture, adding it to the list of university courses and deepening mutual cultural understanding.

4) Transportation connectivity: As early as the early 20th century, the construction of the Chinese Eastern Railroad was completed, laying a solid foundation for the development of China-Russia financial cooperation. In recent years, water transport lines, railway lines and civil aviation lines have been built in succession, which to a large extent has promoted cross-border cooperation. In order to establish long-term cooperative relations, Russia has formulated the 2030 railway construction plan to promote the development of financial cooperation with China with a number of railway roads.

\section{B. Disadvantages of the financial cooperation}

1) Both are developing countries, and their economic strength needs to be improved: As both China and Russia are developing countries, their economic strength is relatively weak compared with that of developed countries, which exposes disadvantages in the financial cooperation between the two countries and severely limits the development pace of the financial cooperation between them. As for Russia, the price of oil has experienced severe collapses, resulting in the country's oil financial crisis. So there is a rather big risk in the cooperation with this country. Therefore, in order to ensure the healthy cooperation between China and Russia, it is necessary to constantly improve the national economic strength.

2) China's financial supporting policies are not comprehensive, hindering the development of the RMB: Although China has launched an open development policy, it lags behind in carrying out supporting financial policies and has not yet improved the contents of various policies. This policy issue has led to the hindering of the development of RMB.

3) Problems in bilateral business cooperation have not yet been effectively resolved: In recent years, 
Chinese and Russian enterprises have developed at a fast speed and there are more and more cooperation projects between the two countries, which have boosted the economic development of the two countries. However, there are still some problems that have not been effectively solved. First, the communication channels are not yet perfect; second, the level of aftersales service of the trading platform needs to be improved; third, the collaboration results are weak due to serious myopic effect.

4) Companies in the two countries use less credit and financing, which limits their scale of development: Due to the weak economic strength of the country, it is necessary to rely on the power of credit financing in order to reach a higher level. However, the two countries have not yet applied this development channel and are faced with financing difficulties, which leads to the slowing down of financial cooperation.

\section{Financial cooperation opportunities}

1) Implementation of resource complementarity under "the Belt and Road Initiative": The proposal of "the Belt and Road Initiative" demonstrates China's wisdom in developing international economy and trade, which is of great help in overcoming the obstacles of financial cooperation and effectively implementing the development of resource complementarity between the two countries. In recent years, under the influence of this policy, international financial institutions have established financial transaction management centers, which have guaranteed the influence of rouble and RMB in international development.

2) The diversified development of the international monetary system: The establishment of a diversified international monetary system has opened up a new path for Financial cooperation between China and Russia. It is important to seize this opportunity to transform the economic system so as to enhance national economic strength. At present, the development of China-Russia cooperation has seized this opportunity and promoted each other's economic development. In the next 10 years, the international monetary system will be improved and diversified, which is an important opportunity for financial cooperation between the two countries.

3) APEC (Asia-pacific Economic Cooperation) has promoted the close economic development of the two countries: Influenced by the financing markets in Europe and the United States, the APEC management organization has imposed restrictions on the Russian economy and trade. During this period, there were many problems in the financial cooperation of other countries in Russia, which led to "common problems" in the international economic and trade cooperation. First, cooperative dependence is high; second, economic development is highly indebted. In order to ensure the healthy growth of its enterprises, Russia urgently needs to establish financial cooperative relations with China. Therefore, the emergence of APEC has prompted Russia and China to establish a close cooperative relationship.

\section{Threats of the financial cooperation}

1) The old order cannot be broken, and the new financial and trade cooperation framework cannot be replaced: At present, the center of the international economic and financial system is still the US dollar, so China and Russia have a relatively weak voice in international economic and trade, which shows the development situation of the old order that is hard to break. However, the international framework implemented by the WTO is of little help to the cooperation between the two countries and presents a marginalized development trend.

2) There are big differences between the two countries' economic development models: During the period of cooperation between China and Russia, there are some differences in the modes of operation and development, namely, economic integration and characteristic economy and the two economic systems pusued by the two are contradictory to each other. Although the characteristic economy contributes to the improvement of the national economic development level, the existence of national differentiation threatens the financial cooperation between the two countries.

3) As competition pressure increases gradually, there are potential financial risks: Although China and Russia have a cooperative relationship, they also compete with each other. The most representative area is the military industry. In order to compete with the United States, the two countries have made great efforts to develop military industry. As a rising star, China has made great progress in military industry development. This development situation has created a beggar-thyneighbor effect, resulting in conflicts between the two countries in cooperation.

\section{SUGGESTIONS ON THE DEVELOPMENT OF CHINA'S FINANCIAL COOPERATION WITH RUSSIA UNDER THE NEW SITUATION}

\section{A. Effective implementation of complementary resources}

With the advantages of "economic complementarity" and "transportation connectivity" in the current cooperation between the two countries, a foundation for the development of resource- 
complementary financial trade has been laid. Under the implementation of "the Belt and Road Initiative", the coordinated development of the industry can be realized through the flow of technology and personnel, so as to maximize the utilization of resources and solve the problem of insufficient resources among each other.

\section{B. Speeding up the reform of the economic and financial systems of the two countries and promoting the economy through culture}

It is difficult to reach consensus on financial cooperation due to the great differences in economic development modes between the two countries. Facing the current trend of development, it is necessary to accelerate the reform of national economic and financial system to lay a foundation for the development of financial cooperation. In view of the frequent cultural exchanges between China and Russia, cultural exchanges can be used to influence the economic and financial system structure and accelerate the reform.

\section{Increasing corporate credit and financing and appropriately reducing trade barriers}

In the fierce competition environment, in order to accelerate the growth pace of enterprises in both countries and solve the problem of insufficient financing, the two sides can try to use credit financing, appropriately reduce trade protection barriers and accept credit financing with the open door, so as to achieve the purpose of expanding enterprise development funds. China and Russia should take the initiative to participate in the credit financing to avoid being marginalized by other countries, so as to enhance the competitiveness of their export trade and at the same time enhance the opportunities of trade exchanges with other countries.

\section{Strengthening economic infrastructure in the two regions}

Economic construction is the cornerstone of national development. In order to promote trade between China and Russia, regional economic infrastructure must be strengthened. In this process, it is necessary to seize the opportunity of APEC to promote the close economic development of the two countries and drive the economic development of enterprises of the two countries, so that enterprises of the two sides can reach consensus on economic and trade development, make up for the shortcomings of each other's enterprises and form a solid local economic foundation. In addition, for the problems encountered during the enterprise cooperation, they should communicate with each other and explore solutions at the first time.

\section{CONCLUSION}

The research is conducted based on the ChinaRussian financial cooperation under the new situation of international financial trade development, which shows that China-Russian cooperation has a great impact on the economic development of the two country. Under the new circumstances, China and Russia should seize the opportunity, strengthen ties with each other, constantly innovate cooperation models, and make the financial sector a powerful booster for the rapid growth of the Chinese and Russian economies, so as to drive the rapid growth of the world economy. At the same time, it is necessary to be aware of the dangers of financial risks and ensure the economic development of the two countries in a safe environment.

\section{References}

[1] Cui Geng Li, Guo Jinghui, Qin Xiaoyan. Financial Cooperation Among Countries Along the Belt and Road" based on SWOT Analysis [J]. Journal of Zaozhuang University, 2020, 37(1): 105-112. (in Chinese)

[2] Li Yang. Financial Cooperation Between Russia and China and Its and Path Choice Under the New Situation [J]. Northeast Asia Forum, 2019, 28(1): 92-101. (in Chinese)

[3] Shi Cheng. Deepening China's Investment Cooperation with Russia Under the New Situation: Risk Factors, Risk Assessment and Prevention Path [J]. Bridge of Century, 2018(6): 50-53. (in Chinese)

[4] Ding Wenli, Liu Fengrui, Li Fuchang. China and the Neighboring Countries of Southeast Asia from the Heterogeneous Multiple Subject Perspective [J]. Finance, 2018, 8 (1): 10. (in Chinese)

[5] Liang Xueqiu. Research on Sino-Russian Financial Cooperation and Future Development $[\mathrm{J}]$. Learning and Exploration,2020(02): 125-130.

[6] Liu Bin. New Situation and Suggestions of China-Russia Financial Cooperation $[\mathrm{J}]$. Practice of Foreign Trade and Economic Cooperation,2019(11): 61-64. 